\title{
YOUR APPLICATION FOR ETERNAL LIFE HAS BEEN PARTIALLY APPROVED
}

\author{
All that matters.
}

\section{BY JAMES WESLEY ROGERS}

$\mathrm{T}$ his is an important message from the Central Existence Committee. Press 1 to receive this message in English. Press 2 to receive this message in Spanish. Press 3 to have this message directly injected into your brain using Chomsky universal grammar. You have three seconds to choose.

Congratulations, Mr Lawson. We have confirmed that you have less than 6 weeks to live. You are now eligible for total fermionic regeneration. Your application has been approved with a continuity coefficient of $0.8(80 \%)$.

You will be regenerated via a process originally developed for quantum teleportation. First, you will be subatomically scanned, using what is referred to as a 'destructive read'. Essentially, your body will be completely destroyed as it is converted into pure information. Next, we will apply powerful error-correcting algorithms to your data, and reconstitute your body with all pathological conditions eliminated. Your data will not be shared with any third party.

During reconstitution, your personality will be slightly altered, using a simple linear interpolation between yourself (80\%) and a standard personality template $(20 \%)$.

Your continuity coefficient of 0.8 (80\%) was determined by a number of factors:

1) Your current profession, astronaut, is considered nonessential. By adjusting your aptitudes, we hope to nudge you towards a more useful vocation, such as obesity counselling or motivational performance art.

2) You have a poor record of separating your recyclables. To have any chance at all of being an effective obesity counsellor, you will need a greater sense of civic responsibility.

3) We have detected a disturbing pattern of negativity towards Canadian pop stars on your social media accounts. Such cynicism and poor aesthetic judgement have no place in an enlightened society.

As your continuity coefficient is less than the legal threshold of $94 \%$ established by Jones- $B$ v. California, your derived self will not legally be Linus Lawson, but rather

\section{$\rightarrow$ NATURE.COM}

Follow Futures:

@ @NatureFutures

f go.nature.com $/ \mathrm{mtoodm}$ your direct descendent, Linus Lawson-B. You may transfer up to $100 \%$ of your current assets to Linus
Lawson-B without probate or inheritance tax. Your academic and professional qualifications will also be transferred, contingent on a series of review examinations.

Linus Lawson-B's age will be legally established as 21 at the time of regeneration. Any contractual agreement, including marriage, to which Linus Lawson is a party may be voided at this time.

Press 1 to review frequently asked questions about fermionic regeneration. Press 2 to proceed directly to the next section. You have three seconds to choose.

Frequently asked questions Will the reconstituted person really be me?

For a continuity coefficient of $1.0(100 \%)$, the general consensus is yes, both legally and ontologically. For lower continuity coefficients, there is much debate.

Ask yourself this: am I the same person when I wake up in the morning as I was the night before? Research has shown that during periods of intense synaptic reorganization, the continuity coefficient of someone waking from a deep sleep can be as low as 0.996 (99.6\%) As neural adaptation and memory degradation accumulate every day, are you still the same person you were one year ago?

It has been postulated that a human being is not one continuous person throughout his or her life, but rather a sequence of discrete persons, each with merely a perception of continuity with the preceding individuals. Perhaps it is this perception of continuity that is the functional definition of a soul. If that is the case, and your derived self has this perception of continuity with you, then he or she will be you in the only meaningful sense.

The most we can say then, is that there is a very high probability that your derived self will have a perception of continuity with you.

What about my loved ones?

All memories of your friends and family members will be transferred, and your derivative self may retain some of your emotional attachment to them.

\section{Will I ever need to be}

(1)

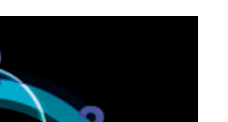
regenerated again?

Barring accident, no. Genetic and cellular improvements made during error correction will result in a derivative body that can be indefinitely maintained in optimal condition by conventional therapies.

Will you keep a back-up of my data?

Unfortunately, this is a practical impossibility. The amount of information needed to encode a human being at the subatomic level is unimaginably huge. At this time, we possess only enough informationstorage capacity to temporarily encode a single human being, and to keep one standard template. The standard personality template was chosen from among the giants of human intellect and accomplishment of the past seven decades.

I've heard that the standard personality template is legendary Canadian pop star Justin Bieber. Is that true?

We can neither confirm nor deny this rumour. End of FAQ

Once again, Mr Lawson, congratulations. You are about to embark on a great adventure. Due to scheduling constraints, your regeneration must begin immediately. Should you choose to decline regeneration at this time, you will not be allowed to reapply. Press 1 to be completely regenerated into a functionally immortal form that will retain $80 \%$ of your current identity. Press 2 to decline regeneration and live for up to 6 more weeks as Linus Lawson. You have three seconds to choose.

James Wesley Rogers sometimes allows computational geometry to distract him from science fiction. These distractions occur most often at a 3D modelling software company in Columbus, Ohio. 